\title{
Maternal Near-Miss Obstetric Events and Maternal Mortality
}

\author{
SHEHLA CHANNA ${ }^{1}$, HINA AKMAL MEMON², NAYAB QASIM ${ }^{3}$, ABDUL RAUF MEMON$^{4}$, IKRAM AHMED TUNIO ${ }^{5}$, NAND \\ LAL SEERANI ${ }^{6}$ \\ ${ }^{1}$ Assistant Professor of Obstetrics \& Gynaecology, LUMHS Jamshoro \\ ${ }^{2,3}$ Women Medical Officers, Liaquat University Hospital Hyderabad \\ ${ }^{4}$ Assistant Professor of Neurosurgey, LUMHS Jamshoro \\ ${ }^{5}$ Associate Professor of Forensic Medicine, Khairpur Medical College, Khairpur Mirs \\ ${ }^{6}$ Assistant Professor of Gastroenterology LUMHS, Jamshoro \\ Correspondence to Dr. Shehla Channa, E-mail: shehlaraza600@gmail.com, +923323630156
}

\begin{abstract}
Aim: To know about the prevalence, characteristic and nature of near miss events and to relate the nature of near miss events with that of maternal mortality.

Study design: Descriptive cross sectional study

Place and duration of study: Department of Obstetrics \& Gynecology Unit IV, LUMHS Jamshoro from $1^{\text {st }}$ January 2020 to $31^{\text {st }}$ December 2020

Methodology: Pregnancy outcomes segregated into maternal death, near-miss event, or live birth categories. Age, level of education, religion, and residence were socio demographic variables. Obstetrics characteristics and nature of maternal near-miss events also studied.

Result: The prevalence of maternal near-miss event was 5.6\%, and the maternal near-miss events were seen more in multigravida, pregnant women with the lack of antenatal care in referral cases. Live birth as fetal outcome was $75 \%$. The maternal death to near-miss ratio in this study was $1: 5.44(42.3 \%)$ postpartum haemorrhage and $28(26.9 \%)$, hypertensive disorders cases were leading cause of maternal near-miss events.

Conclusion: Every fifth women who survived life-threatening complications, one died. Maternal near-miss should be adopted as an indicator for evaluating maternal health services.

Keywords: Maternal near-miss (MNM), Maternal mortality, Life-threatening complication
\end{abstract}

\section{INTRODUCTION}

Demise of a mother during labor hits the foundation of the family. ${ }^{1}$ The discouraging actuality behind this figure is that the majority of the maternal expiries can be prevented. ${ }^{2}$ Maternal mortality is a significant pointer for the estimation of maternal wellbeing. ${ }^{3}$ Pregnant ladies' wellbeing status isn't reflected by death markers only. Subsequently, the idea $\mathrm{MNM}$ is adept for the current health giving framework. ${ }^{4,5}$ Maternal near-miss (MNM) case is described as "a woman who nearly died but survived a complication that occurred during pregnancy, childbirth, or within 42 days of termination of pregnancy". ${ }^{6}$ Investigation of MNM cases assists with recognizing what turns out badly in pregnancy related care..$^{7-10}$ It features the nature of obstetrics care and gives significant data in distinguishing the elements that lead to maternal passing. ${ }^{11-14}$

Near-miss/SAMM cases are of extensive interest to obstetricians and medical services chiefs as it help assess the inadequacies in ladies medical care offices and recognize the potential zones. ${ }^{15}$. Maternal near-miss helps in coming to an obvious conclusion of the course of occasions which at last finished in maternal demise. This idea likewise permits inception of mindfulness based preventive projects to upgrade the nature of maternal medical care. Examination of maternal mortality with these cases helps in inspecting individual, social, monetary, and underlying indicators of maternal mortality. ${ }^{16}$ Compelling execution of the MNM idea will help examine the high-

Received on 13-01-2021

Accepted on 27-04-2021 hazard bunch, plan applicable intercessions for managing obstetric crises, and build up the whole medical services arrangement for empowering good result. ${ }^{17}$ Burden of MNM events is high and these need to be identified and managed at the earliest. ${ }^{3}$

We get an enormous number of referred cases from a large portion of the provincial hospitals of whole Sindh what's more, which here and there land up in mortality so we arranged this study to discover the recurrence of maternal MNM occasions and compare at the idea of MNM events with maternal demise. What's more, as indicated by WHO measures, exact insights are most certainly not accessible from these moms. Thinking about this hole and need for total data for strategy and choice making on decreasing maternal horribleness and mortalities, the motivation behind this study was to determine the prevalence, characteristic and nature of MNM events, socio demographic and obstetric determinant factors associated with these, to compare the nature of MNM events with that of maternal mortality.

\section{MATERIALS AND METHODS}

This cross sectional descriptive study conducted in the Department of Obstetrics \& Gynecology, LUMHS Jamshoro from $1^{\text {st }}$ January 2020 to $31^{\text {st }}$ December 2020. Women who had a spontaneous abortion or other pregnancy loss excluded from the study. Pregnancy outcomes segregated into maternal death, near-miss event, or live birth categories. Age, level of education, religion, and residence were socio demographic variables. Obstetrics characteristics and nature of MNM events also studied. All data entered into SPSS-24. 


\section{RESULTS}

The socio demographic detail of the present study indicates that $75 \%$ of the women were in the age group of 20 to 30 years. $63 \%$ of the women residing in the rural areas while $36.5 \%$ from urban areas. The women with no formal education were more than twice those of primary and secondary educated women. $89.4 \%$ were Muslim women while $10.6 \%$ were non-Muslim. $75.9 \%$ of the patients were in third trimester at the gestational age of more than 32 weeks. Whereas $15.4 \%$ were postnatal and $8.7 \%$ were less than 32 weeks ([Table 1).

Table 1: Demographic information of the women $(n=104)$

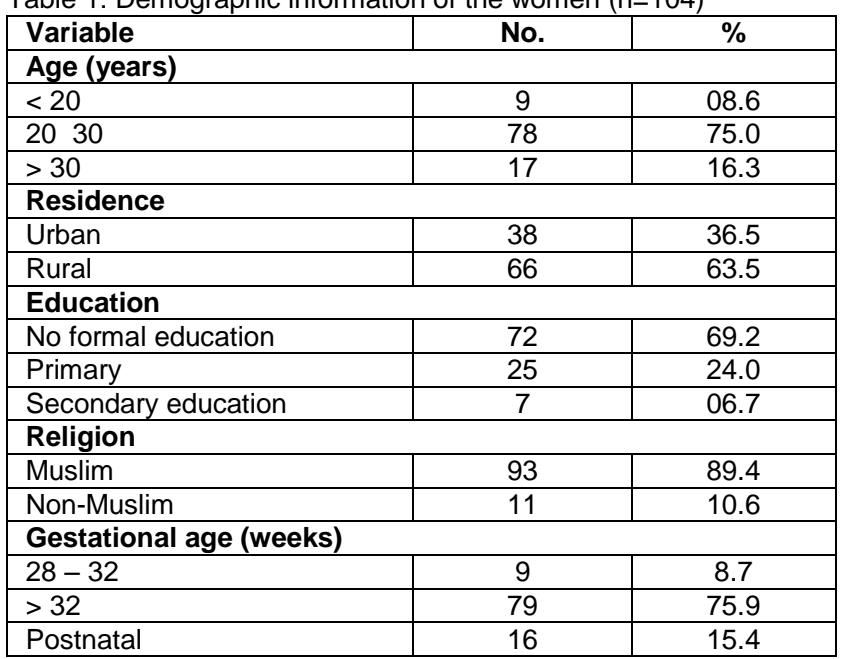

Table 2: Prevalence and attributes of MNM events

\begin{tabular}{|c|c|c|}
\hline Variable & No. & $\%$ \\
\hline \multicolumn{3}{|l|}{ Referral status } \\
\hline Self-referred & 37 & 35.6 \\
\hline Referred from primary health facility & 49 & 47.1 \\
\hline During Hospitalization & 18 & 17.3 \\
\hline \multicolumn{3}{|l|}{ Booking status } \\
\hline Booked & 36 & 34.6 \\
\hline Un-booked & 68 & 65.4 \\
\hline \multicolumn{3}{|l|}{ Hospital stay } \\
\hline HDU & 26 & 25.0 \\
\hline ICU & 13 & 12.5 \\
\hline Ward admission & 65 & 62.5 \\
\hline \multicolumn{3}{|l|}{ Fetal outcome } \\
\hline Live birth & 78 & 75.0 \\
\hline Still birth & 10 & 9.6 \\
\hline Early neonatal death & 16 & 15.4 \\
\hline \multicolumn{3}{|l|}{ Antenatal care } \\
\hline Yes & 23 & 22.1 \\
\hline No & 61 & 58.6 \\
\hline \multicolumn{3}{|l|}{ Gravidity } \\
\hline Prime gravid & 46 & 44.1 \\
\hline Multigravida & 54 & 51.9 \\
\hline Maternal death & 21 & 20.2 \\
\hline Maternal death to MNM ratio & \multicolumn{2}{|c|}{$1: 5$} \\
\hline
\end{tabular}

There were 2024 obstetric admissions, where number of deliveries are 1941. Out of which 1869 were live births and $104(5.6 \%)$ were maternal MNM cases. From the MNM cases, $18(17.3 \%)$ were hospitalized and remaining were refereed cases out of which $35.6 \%$ were self-refereed and
$47.1 \%$ were referred from primary health facility. $34.6 \%$ patients were booked while $65.3 \%$ were un-booked. $12.5 \%$ women were admitted to ICU with the MNM, 25\% were admitted in high dependency unit and $62.5 \%$ MNM were in the ward. As for fetal outcome, $75 \%$ were live birth, $9.6 \%$ were stillbirth and $15.4 \%$ were early neonatal death. $58.5 \%$ did not take antenatal care whereas $22.1 \%$ took the antenatal care. $59.1 \%$ of the woman with MNM cases were multigravida whereas $44.2 \%$ were prime gravid (Table 2 ).

From the causes of MNM, 14 (13.4\%) were sepsis cases, $44(42.3 \%)$ were postpartum haemorrhage, 18 (17.3\%) were ruptured uterus and 28 (26.9\%) were Hypertensive disorders cases. From total sepsis cases 10 (9.6\%) were MNM and 4 (3.8 \%) was maternal death. From total Postpartum Haemorrhage cases 36 (34.61\%) were MNM and maternal death was $8(7.69 \%)$. From total of Ruptured uterus cases $16(15.38 \%)$ were MNM cases and 2 (1.92\%) maternal deaths. From total of Hypertensive disorders cases $25(24.03 \%)$ were MNM with the mortality rate of 3 (2.88\%) [Table 3).

Table 3: Nature of MNM ( $\mathrm{n} 104)$

\begin{tabular}{|l|c|c|c|c|c|c|}
\hline $\begin{array}{l}\text { Nature of } \\
\text { MNM }\end{array}$ & Total & $\%$ & MNM & $\%$ & Mortality & $\%$ \\
\hline Sepsis & 14 & 13.4 & 10 & 9.6 & 4 & 3.8 \\
\hline $\begin{array}{l}\text { Postpartum } \\
\text { haemorrhage }\end{array}$ & 44 & 42.3 & 36 & 34.61 & 8 & 7.69 \\
\hline $\begin{array}{l}\text { Ruptured } \\
\text { uterus }\end{array}$ & 18 & 17.3 & 16 & 15.38 & 2 & 1.92 \\
\hline $\begin{array}{l}\text { Hypertensive } \\
\text { disorders }\end{array}$ & 28 & 26.9 & 25 & 24.03 & 3 & 2.88 \\
\hline
\end{tabular}

\section{DISCUSSION}

Maternal mortality was utilized to address the nature of obstetric consideration yet better evaluation of obstetrical consideration presently incorporates MNM cases and events to be a valuable apparatus for assessment of maternal mortality. To handle maternal passing, clear comprehension of the pervasiveness and properties in a given setting is vital.

In the current study, the pervasiveness of MNM cases was $5.6 \%$. The maternal demise to approach miss proportion was 1:5. This demonstrates that for each 5 ladies who survived life threatening complications, one passed on. This finding is in accordance with other study demonstrating maternal demise to MNM proportion 1:5. ${ }^{10}$ This proportion is characteristic of the norm of obstetrical consideration the unit offers. This is as opposed to what saw in underdeveloped nations of the world. Studies completed in Europe ${ }^{18}$ uncovered a proportion of $1: 117$, though in Nigeria ${ }^{19}$ the proportion is $1: 11$.

Present study has found the hospitalized patients provided with immediate care within the hospital so less MNM event occurred while self-referral and referred from primary health facility care was delayed so high MNM events observed. This finding is in line with the Tigray regional state hospitals with instant care provided for hospitalized patients ${ }^{20}$ and in line with the morocco study where delayed occurred in providing care to the referral case. ${ }^{21}$ Most referred from other health facilities due to poor infrastructure and/or inability of health personnel in managing the conditions, leading to delay. ${ }^{22}$ The cases of MNM were less likely for those who were booked. This 
finding is similar with the observations made by other authors. ${ }^{23-25}$

The ICU admission with MNM was $12.5 \%$, which is lower than HDU and ward admission. This finding is in line with the figure observed in other studies. ${ }^{26,27}$ The low rate of ICU admission indicates a shortage of ICU beds as the hospital has a common ICU with a few beds for obstetric patients. As for the fetal outcome, live birth observed to be $75 \%$, stillbirth reported as $9.6 \%$ of MNM and early neonatal death identified to be $15.4 \%$. This findings is contrary with WHO multi-country survey where the risk of late fetal deaths and early neonatal mortality to be significantly higher. ${ }^{28}$

Moms with no ANC were threefold bound to have a maternal MNM event contrasted with moms who got Antenatal consideration. This finding is in accordance with the investigations directed in Ethiopia where they tracked down a comparative connection between Antenatal consideration and maternal MNM cases. ${ }^{29,30}$

Present investigation found that multigravida moms were at expanded danger of maternal MNM contrasted with primigravida moms. It is validating with the Philippines study. ${ }^{29}$ Therefore, education and family planning methods should be encouraged.

Around the world, practically all reasons for maternal mortality and MNM are preventable. ${ }^{22}$ The significant reasons for maternal MNM distinguished in this study; $34.61 \%$ were postpartum hemorrhage, $24.03 \%$ hypertensive disorders, $15.38 \%$ ruptured uterus $9.6 \%$ sepsis. This finding is similar to what reported previously in the WHO multi country survey (31)where $\mathrm{PPH}$ was the cause of severe maternal morbidity in women from Pakistan. ${ }^{32}$ Abdollahpour ${ }^{33}$ in his systemic review and met analysis of 49 research articles reports the global prevalence of Maternal MNM of 18.67/1000, in his conclusion he tells us about the critical and direct connection among MNM and maternal demise. This implies that vacillations in a single lead to another change. Subsequently, the maternal mortality record can be thought of as the most dependable pointer in the evaluation of maternal wellbeing. In view of this file, nations ought to set up a public medical care framework for increment standard and wellbeing practices of health suppliers

\section{CONCLUSION}

The burden of MNM and severe morbidity in our hospital is high. This translates to a significant adverse effect on maternal and foetal outcomes and a burden on health services, so. Strategies should be developed to identify lifethreatening conditions early, so that such cases reach the appropriate facility in time to prevent maternal and perinatal mortality and morbidity. Quality antenatal, essential and emergency obstetric care should be made available and accessible to all. Further, the availability of HDO and ICU would be of help to patients of severe MNM because of timely care provided by the facilities.

\section{REFERENCES}

1. Tajik P, Nedjat S, Afshar NE, Changizi N, Yazdizadeh B, Azemikhah A, et al. Inequality in maternal mortality in Iran: an ecologic study. Int J Prevent Med 2012;3(2):116.
2. Abha S, Chandrashekhar S, Sonal D. Maternal MNM: A valuable contribution in maternal care. J Obstet Gynecol India. 2016;66(1):217-22.

3. Alkema L, Chou D, Hogan D, Zhang S, Moller A-B, Gemmill $A$, et al. Global, regional, and national levels and trends in maternal mortality between 1990 and 2015, with scenariobased projections to 2030: a systematic analysis by the UN Maternal Mortality Estimation Inter-Agency Group. Lancet 2016;387(10017):462-74.

4. Stones W, Lim W, Al-Azzawi F, Kelly M. An investigation of maternal morbidity with identification of lifethreatening'MNM' episodes. Health Trends 1991;23(1):13-5.

5. Sivalingam N, Looi K. Clinical experience with management of" near-miss" cases in obstetrics. Med J Malaysia 1999;54(4):496-503.

6. Say L, Souza JP, Pattinson RC. Maternal MNM-towards a standard tool for monitoring quality of maternal health care. Best Prac Res Clin Obstet Gynaecol 2009;23(3):287-96.

7. Filippi V, Ronsmans C, Gohou V, Goufodji S, Lardi M, Sahel $A$, et al. Maternity wards or emergency obstetric rooms? Incidence of near-miss events in African hospitals. Acta obstetricia et gynecologica Scandinavica 2005;84(1):11-6.

8. Souza JP, Cecatti JG, Haddad SM, Parpinelli MA, Costa $\mathrm{ML}$, Katz L, et al. The WHO maternal near-miss approach and the maternal severity index model (MSI): tools for assessing the management of severe maternal morbidity. PloS One 2012;7(8):e44129.

9. Organization $\mathrm{WH}$. Evaluating the quality of care for severe pregnancy complications: the WHO near-miss approach for maternal health. 2011.

10. Oladapo OT, Sule-Odu AO, Olatunji AO, Daniel OJ. " Nearmiss" obstetric events and maternal deaths in Sagamu, Nigeria: a retrospective study. Reproduc Health 2005;2(1):19 .

11. Abdel-Raheem SS, Mahran DG, Al-Attar GS, Qayed MH, Zareh ZE, Othman EE-DR. Magnitude and pattern of maternal near-miss cases admitted to Women's Health Hospital, Assiut University. J Curr Med Res Prac 2016;1(3):92.

12. Chhabra P. Maternal MNM: an indicator for maternal health and maternal care. Indian J Comm Med 2014;39(3):132.

13. Kumela L, Tilahun T, Kifle D. Determinants of maternal MNM in Western Ethiopia. Ethiopian $J$ Health Sci 2020;30(2).

14. Abdel-Raheem SS, Al-Attar GS, Mahran DG, Qayed MH, Alib Z-AZ, Othman EE-DR. Delays associated with maternal near-miss cases admitted in Women's Health Hospital, Assiut University. J Curr Med Res Prac 2017;2(1):1.

15. Say L, Souza J, Pattinson R. WHO maternal deaths and near-miss classifications. Bull WHO 2009;87:734.

16. Mbachu II, Ezeama C, Osuagwu K, Umeononihu OS, Obiannika C, Ezeama N. A cross sectional study of maternal MNM and mortality at a rural tertiary centre in southern nigeria. BMC Pregnan Childbirth 2017;17(1):1-8.

17. Sultana S, Ishtiaque S, Fareed S, Kamal S, Aslam Z, Hussain $R$, et al. Clinical spectrum of near-miss cases in obstetrics. Cureus 2019;11(5).

18. Minkauskienè M, Nadišauskienè R, Padaiga Ž, Makari S. Systematic review on the incidence and prevalence of severe maternal morbidity. Medicina. 2004;40(4):299-309.

19. Prual A, Huguet D, Garbin O, Rabe G. Severe obstetric morbidity of the third trimester, delivery and early puerperium in Niamey (Niger). Afr $\mathrm{J}$ Reprod Health 1998;2(1):10-9.

20. Filippi V, Chou D, Ronsmans C, Graham W, Say L. Levels and causes of maternal mortality and morbidity. 2016.

21. Assarag B, Dujardin B, Delamou A, Meski F-Z, De Brouwere $\checkmark$. Determinants of maternal near-miss in Morocco: too late, too far, too sloppy? PloS one 2015;10(1):e0116675. 
22. Ameyaw EK, Dickson KS. Skilled birth attendance in Sierra Leone, Niger, and Mali: analysis of demographic and health surveys. BMC Public Health 2020;20(1):164.

23. Jabir M, Abdul-Salam I, Suheil DM, Al-Hilli W, Abul-Hassan $\mathrm{S}$, Al-Zuheiri A, et al. Maternal MNM and quality of maternal health care in Baghdad, Iraq. BMC Pregnancy Childbirth 2013; 13(1):1-9.

24. Galvão LPL, Alvim-Pereira F, de Mendonça CMM, Menezes FEF, do Nascimento Góis KA, Ribeiro Jr RF, et al. The prevalence of severe maternal morbidity and MNM and associated factors in Sergipe, Northeast Brazil. BMC Pregnancy Childbirth 2014;14(1):1-8.

25. Pandey A, Das V, Agarwal A, Agrawal S, Misra D, Jaiswal $\mathrm{N}$. Evaluation of obstetric MNM and maternal deaths in a tertiary care hospital in north India: shifting focus from mortality to morbidity. J Obstet Gynecol India 2014; 64(6): 394-9.

26. Norhayati MN, Hazlina NHN, Sulaiman Z, Azman MY. Severe maternal morbidity and MNMes in tertiary hospitals, Kelantan, Malaysia: a cross-sectional study. BMC Public Health 2016;16(1):1-13.

27. Siddiqui SA, Soomro N, Hasnain F. Severe obstetric morbidity and its outcome in patients presenting in a tertiary care hospital of Karachi. JPMA 2012;62(3):226.

28. Vogel JP, Souza J, Mori R, Morisaki N, Lumbiganon P, Laopaiboon $\mathrm{M}$, et al. Maternal complications and perinatal mortality: findings of the World Health Organization
Multicountry Survey on Maternal and Newborn Health. BJOG 2014;121:76-88.

29. Nair M, Kurinczuk J, Brocklehurst P, Sellers S, Lewis G, Knight $M$. Factors associated with maternal death from direct pregnancy complications: a UK national case-control study. BJOG 2015;122(5):653-62.

30. Dile M, Abate T, Seyum T. Proportion of maternal MNMes and associated factors in referral hospitals of Amhara regional state, Northwest Ethiopia: institution based cross sectional study. Gynecol Obstet (Sunnyvale) 2015;5(308):2161-0932.1000.

31. Kulkarni R, Chauhan S, Daver R, Nandanwar Y, Patil A, Bhosale A. Prospective observational study of near-miss obstetric events at two tertiary hospitals in Mumbai, Maharashtra, India. Int J Gynecol Obstet 2016;132(2):170-3.

32. Kassebaum NJ, Bertozzi-Villa A, Coggeshall MS, Shackelford KA, Steiner C, Heuton KR, et al. Global, regional, and national levels and causes of maternal mortality during 1990-2013: a systematic analysis for the Global Burden of Disease Study 2013. Lancet 2014; 384(9947):980-1004

33. Abdollahpour S, Miri HH, Khadivzadeh T. The global prevalence of maternal MNM: a systematic review and meta-analysis. Health Promotion Perspectives 2019;9(4):255 